\title{
CONHECENDO O CÉREBRO 2018: INTERDISCIPLINARIDADE EM UM EVENTO DE EXTENSÃO
}

\author{
Livia Langner Langner \\ Universidade Estadual do Norte do Paraná \\ langnerlivia@gmail.com \\ Natãny Aparecida Paduan \\ Universidade Estadual do Norte do Paraná \\ natany_paduan@hotmail.com \\ Gabriel Martins Gomes \\ Universidade Estadual do Norte do Paraná \\ gabrielgomes@setupjr.com.br
}

Murillo Di Angelis Aguilera

Universidade Estadual do Norte do Paraná murillo.a.a@hotmail.com

Juliane Priscila Sachs

Universidade Estadual do Norte do Paraná jsachs@ffalm.br

Bruna Larissa Ramalho Diniz Universidade Estadual do Norte do Paraná bruna.diniz@uenp.edu.br

Roberta Ekuni

Universidade Estadual do Norte do Paraná robertaekuni@uenp.edu.br

Resumo

O "Conhecendo o Cérebro" é um evento interdisciplinar, organizado pelo Programa de Extensão Grupo de Estudos em Neurociência, que convida outros projetos da universidade de acordo com a temática proposta para a Semana Nacional de Ciência e Tecnologia. Realizado em outubro de 2018, o mesmo teve como objetivo divulgar Ciência para crianças e adolescentes da Educação Básica da região. Como método, organizou os estandes a partir da temática "Ciência para redução de desigualdades", contemplando estandes sobre neurociência, equidade de gênero, agronomia, materiais didáticos para cegos no ensino de Biologia e estande de tecnologia. Como resultado, foram mobilizados quatro docentes, 46 alunos de graduação, e um colaborador externo, englobando três cursos de graduação da UENP. Mais de 570 pessoas visitaram o evento e interagiram com os monitores. Conclui-se que o evento atingiu seu objetivo de interagir com a comunidade, divulgando Ciência em um ambiente não-formal de ensino, contribuindo tanto para a formação dos alunos quanto para com a popularização da ciência para a comunidade.

Palavras-chave: Extensão Universitária. Divulgação Científica. Relações Instituição/Comunidade.

\section{KNOWING THE BRAIN 2018: INTERDISCIPLINARITY IN AN EXTENSION EVENT}

Abstract

The "Knowing the brain" is an interdisciplinary event, organized by the Neuroscience Study Group Extension Program, which invites other projects from the university according to the theme proposed for the National Week of Science and Technology. Held in October 2018, it aimed to disseminate science to children and adolescents of Basic Education in the region. As a method, we organized stands based on the theme "Science to reduce inequalities", including stands on neuroscience, gender equity, agronomy, teaching materials for the blind in the teaching of biology and technology stand. As a result, four professors, 46 undergraduate students, and one external collaborator were mobilized, encompassing three UENP undergraduate courses. More than 570 people visited the event and interacted with the monitors. It is concluded that the event reached its goal of interacting with the community, disseminating science in a non-formal teaching environment, contributing both to the education of students and the popularization of science to the community.

Keywords: University Extension. Scientific Divulgation. Institution/Community Relations.

\section{CONOCIENDO EL CEREBRO 2018: LA INTERDISCIPLINARIEDAD EVENTO DE EXTENSIÓN}

Resumen

El "Conociendo el cerebro" es un evento interdisciplinario, organizado por el Programa de Extensión Grupo de Estudios en neurociencia, que invita a otros proyectos de la universidad de acuerdo com la temática propuesta para la Semana Nacional de Ciencia y Tecnología. Realizado em octubre de 2018, el mismo tenía como objetivo divulgar ciencia para niños y adolescentes de educación básica em la región. Como método, organizo los expositores a partir de la temática "Ciencia para reducción de desigualdades", contemplando expositores sobre neurociencia, equidad de género, agronomía, materiales didácticos para ciegos em la enseñanza de biología y stand de tecnología. Como resultado, se movilizaron cuatro profesores, 46 estudiantes de grado, y un colaborador externo, abarcando tres cursos de graduación de la UENP. Más de 570 personas visitaronel evento e interactuaron con los monitores. Se concluye que el evento alcanzósu objetivo de interactuar con la comunidad, divulgando ciência en un ambiente no formal de enseñanza, contribuyendo tanto a laformación de los alunos, como a la popularización de la ciencia para la comunidad.

Palavras clave: Extensión Universitaria. Divulgación Científica. Relaciones Institución/Comunidad. 
Conhecendo o cérebro 2018: interdisciplinaridade em um evento de extensão

\section{INTRODUÇÃO}

A divulgação científica é o ato de comunicar achados da Ciência para o público leigo em uma linguagem acessível (BUENO, 2010). Uma forma divertida de se divulgar Ciência pode se dar por meio de exposições, feiras de ciência e museus, ou seja, em ambientes não-formais de ensino (FRANCISCO; SANTOS, 2014). Consideramos como espaço não-formal de ensino os locais e eventos planejados para promover atividades educativas, divulgação científica e sensibilização para a Ciência. Esses espaços recebem visitantes em suas dependências e, com ou sem o auxílio de monitores, desenvolvem programas e atividades que auxiliam na popularização da Ciência e na divulgação científica, conectando os avanços e as questões relacionadas à Ciência, tecnologia, escola e ao cidadão comum (SABBATINI, 2003; LORENZETTTI, 2000).

Um ambiente não-formal de ensino pode despertar a curiosidade das crianças para a Ciência (TOKUHAMA-ESPINOSA, 2013). Além disso, as atividades nesses ambientes são importantes não somente por se constituírem em locais propícios ao processo de aprendizagem de conteúdos escolares, mas também pelas experiências socioculturais que oportunizam, sendo válidas se forem realizadas tanto com o grupo escolar quanto com a família, amigos ou mesmo sozinho (ARAUJO; CALUZI; CALDEIRA, 2006).

Diante disso, o Programa de Extensão Grupo de Estudos de Neurociência (GEN) participa desde 2014 da Semana Nacional de Ciência e Tecnologia (SNCT), com o evento "Conhecendo o Cérebro", realizado no formato de exposição, no estilo feira de Ciências. Inicialmente, o evento abordava somente conteúdo da neurociência (SOUZA et al., 2016). Entretanto, a partir de 2016, o mesmo vem priorizado a interdisciplinaridade, convidando outros projetos de extensão e grupos de pesquisa para participarem do mesmo (e.g. MACACARE et al., 2019). Isso é importante, pois muitos alunos atuam somente com pesquisa, outros não participam de nenhum projeto, mas são recrutados pelos professores para serem treinados para essa ação extensionista. Consequentemente, mais alunos podem ter uma experiência com a extensão universitária. Isso é relevante, pois quando o aluno atua nesse tipo de ação, há aprendizado tanto para quem oferta a ação quanto para quem a recebe (COELHO, 2014).

Em 2018, a SNCT teve como temática "Redução das Desigualdades". Desse modo, a maioria das atividades foi norteada para divulgar atividades cuja temática focava em como a ciência pode contribuir na redução de desigualdades sociais. Os estandes das diversas áreas do conhecimento foram: neurociência, tecnologia, agricultura, equidade de gênero e ensino de ciências para cegos. Todos os estandes foram planejados para serem disponibilizados de maneira 
Conhecendo o cérebro 2018: interdisciplinaridade em um evento de extensão

clara, atrativa e sustentável. A maioria dos materiais didáticos foi feito a partir de materiais reciclados e de simples confecção e manuseio.

Visto que ações de extensão com eventos que visam à popularização da Ciência para a comunidade são importantes para a sociedade, o objetivo deste é relatar a experiência dessa edição do evento "Conhecendo o Cérebro".

\section{MATERIAIS E MÉTODOS}

Proposta do evento

Trata-se de um evento de divulgação e popularização da Ciência, voltado para crianças e adolescentes, que aconteceu nos dias 17 e 18 de outubro de 2018 na Universidade Estadual do Norte do Paraná (UENP) - Campus Luiz Meneghel. O mesmo foi organizado pelo Grupo de Estudos de Neurociência e teve a colaboração de alunos e professores da Universidade.

Cada estande foi orientado por um/a docente que, juntamente com os alunos, estudaram e se prepararam para serem expositores nos dias do evento. As exceções foram o GEAK (Grupo de Estudos em Agroecologia Kaa’pora) e a Setup Jr - Consultoria e Desenvolvimento, uma empresa júnior, cujas coordenações ficaram a cargo de alunos da instituição. Escolas da cidade e região foram convidadas por meio de folder virtual, enviado via redes sociais.

Para a estimativa da quantidade de visitantes nos dias do evento, um livro de visitas foi disponibilizado na entrada (os visitantes poderiam colocar ali nome, sexo, idade e escola). Em relação à análise dos resultados, o mesmo foi baseado na observação participante da interação dos expositores com os visitantes dos estandes.

Estande do Grupo de Estudos em Neurociência

Nesta edição, o estande do GEN foi subdividido em quatro estandes, com a participação de 9 expositores: i) Estande da Lógica, no qual os visitantes interagiam com as atividades de raciocínio lógico utilizando o Tangram e a Torre de Hanói, que foram confeccionados pelos organizadores do estande com materiais recicláveis. Os mesmos ensinavam aos visitantes como fazer os brinquedos em casa, por meio de um manual impresso; ii) Musicalizando: nesse estande as monitoram utilizaram garrafas de plástico e vidro com água ou grãos e demostraram a importância da música e a possibilidade de fazer música e arte com materiais recicláveis, bem como demonstrar que a música serve como forma de expressão; iii) Neuroanatomia: esse estande 
Conhecendo o cérebro 2018: interdisciplinaridade em um evento de extensão

visava explicar a importância das áreas cerebrais com peças reais do Sistema Nervoso Central e algumas partes do Sistema Nervoso Periférico. Também se encontrava disponível um modelo anatômico de um cérebro de plástico (3Bscientific) e um "capacete" de papel, no qual era possível visualizar a separação dos lobos de modo didático; e iv) Ensinando Neurociência com Práticas Artísticas: o objetivo foi complementar as explicações do estande de neuroanatomia de maneira criativa. As monitoras demostraram, por meio de modelos didáticos, as meninges que protegem o cérebro, as funções das células Glias, os lobos e hemisférios utilizados. As explicações e modelos se basearam no livro Caçadores de Neuromitos KIDS: em busca da verdade sobre o cérebro (ZEGGIO, EKUNI, BUENO, 2018).

Estande: O papel da agricultura na redução das desigualdades sociais

Organizado sobre a responsabilidade do Núcleo de Investigação em Tecnologia de Aplicação e Máquinas Agrícolas (NITEC), o presente estande envolveu nove expositores, que mostraram como a agricultura pode reduzir as desigualdades sociais e como ela é fundamental para o cotidiano de todos. Três cartazes foram apresentados com condução oratória, que variava dependendo da idade do público presente no momento. Por exemplo, quando o público era constituído por crianças, havia uma instigação com perguntas do tipo: "o que vocês sabem sobre a agricultura? Vocês conhecem alguma pessoa que trabalha com agricultura? Vocês sabem o que é grande e pequeno produtor?". Baseado nas respostas, explicava-se a diferença entre grandes e pequenos produtores, e que ambos são importantes para a produção de alimento. Em seguida, explicava-se o agronegócio e como o setor da agricultura cresce no Brasil, sendo umas das maiores fontes de riqueza no país e responsável por boa fatia do PIB (Produto Interno Bruto) (JANK; NASSAR; TACHINARDI, 2005).

No segundo momento, por meio de uma data show, exibiam-se algumas diferenças de grandes e pequenos produtores, e que o grande produtor pode ter mais recursos, como a utilização da tecnologia (GUILHOTO et al., 2006), como, por exemplo, o drone. Porém, sempre era destacado que mesmo que o grande produtor tenha vários recursos tecnológicos, mais terras (GUILHOTO et al., 2006), ele não é melhor do que o pequeno produtor, porque ambos produzem a mesma qualidade de alimento.

Para finalizar a visita nesse estande, uma dinâmica era realizada, no qual havia uma "pista" no chão feita com fita adesiva, na qual três alunos participavam de uma "corrida" com várias perguntas relacionadas com o assunto. Quem acertava, caminhava um passo na pista; quem chegava em primeiro lugar, ganhava a corrida. 
Conhecendo o cérebro 2018: interdisciplinaridade em um evento de extensão

Estande do GEAK (Grupo de Estudos Sobre Agroecologia Kaa’pora)

No estande do GEAK (Grupo de Estudos Sobre Agroecologia Kaa’pora), um aluno foi o responsável pela coordenação do estande e outros 7 expositores auxiliaram na execução do mesmo. Tendo a Agroecologia como base ideológica, ou seja, a ciência que prevê o manejo ecológico dos recursos naturais, para gerenciar um agroecossistema sustentável (ALTIERI, 2012), o estande focou na importância desse estilo de vida que beneficia tanto o dono da terra como todos componentes bióticos e abióticos que rodeiam este meio. Tendo isso em mente e baseado na temática "Ciência para a redução de desigualdades", foram abordados os temas: divisão econômica e de terras, diversidade etnobotânica, segurança alimentar e participação dos gêneros na agricultura.

Por meio de um mapa mental em formato circular, os visitantes visualizavam as frentes sociais e as bases ideológicas que envolvem a agroecologia, e com auxílio de uma maquete didática demonstrou-se a diferença entre um grande produtor de monocultura e o pequeno produtor familiar. Assim, foi possível mostrar, por meio de imagens de trabalhadores rurais, tanto a desigualdade no meio rural, quanto a importância da produção familiar para a natureza e sociedade (REAL; SCHNEIDER, 2011). Por fim, os visitantes viram a exposição de mudas de árvores nativas e diferentes sementes crioulas de uso comum a esse tipo de produção do produtor agroflorestal.

Estande: A ciência dos sentidos

Cinco expositores, alunos do curso de Ciências Biológicas, auxiliaram nesse estande cujo objetivo foi explorar alguns sentidos dos visitantes. Para isso, foram utilizados atividades e materiais pedagógicos de áreas específicas das disciplinas escolares de Ciências e Biologia que eram voltados, principalmente, aos deficientes visuais. Os materiais eram de baixo custo e fácil acesso, como plantas, rochas, tipos de solo e modelos pedagógicos feitos a partir de sucata. Ao passarem pelo estande, todos os visitantes tinham seus olhos vendados e, ao mesmo tempo em que exploravam os materiais expostos por meio do tato, olfato e audição, ouviam as explicações científicas dadas pelos expositores.

É sabido que a limitação total ou parcial da visão possui várias implicações que refletem no cotidiano de um indivíduo e a percepção do mundo para a pessoa que não vê acontece por meio dos outros sentidos(SMITH, 2008). O tato, de acordo com Ochaíta e Espinosa (2004), é o 
Conhecendo o cérebro 2018: interdisciplinaridade em um evento de extensão

sentido mais utilizado pelos deficientes visuais, sendo que essa forma de exploração despende muito mais tempo para coletar as informações sobre os objetos que um simples projetar do olhar de um vidente. Assim, segundo a Fundação Catarinense de Educação Especial (FCEE), o estudante cego deve ser constantemente estimulado, principalmente no que diz respeito ao tato, pois esse sentido auxiliará na construção do conhecimento, em como interpretar o mundo por meio desse sentido (SANTA CATARINA, 2011).

Outro sentido muito importante para o deficiente visual é a audição, uma vez que esta permite a comunicação com outras pessoas e, por conseguinte, possibilita a obtenção de informações (por descrição verbal) através desses interlocutores (SMITH, 2008).

No estande também estava disponível um modelo de alfabeto Braille, montado a partir de papelão e papel E.V.A. Após conhecerem o alfabeto, os visitantes eram desafiados a descobrirem o nome dos animais escritos em Braille usando apenas o tato e o som relacionado a cada um. Os visitantes também tiveram a oportunidade de conhecer, por meio de uma breve apresentação audiovisual no Powerpoint, locais como museus, parques e galerias localizados no Brasil e no mundo que facilitam e incentivam o acesso e a visita de deficientes visuais às suas instalações $\mathrm{e}$ exposições.

Estande: Tecnologia com Setup Jr

A empresa júnior Setup Jr - Consultoria e Desenvolvimento foi responsável por esse estande que contou com seis membros (alunos do curso de Ciência da Computação), sendo um deles o coordenador. Os objetivos do estande foram: demonstrar a diferença da forma como um computador "pensa" de nós seres humanos, especificamente no raciocínio (NAVEGA, 2000). Além disso, seguindo a temática do evento "Ciência para a redução de desigualdades", com o auxílio da ferramenta Scratch (https://scratch.mit.edu/), foram apontados novos caminhos e formas de modelar a estrutura de como pensar sobre determinado problema, por meio da lógica de programação. Essa ferramenta destaca-se por possuir uma interface visual fácil, simples e intuitiva, tratando estruturas importantes das linguagens de programação, tais como: blocos de repetições, ações, variáveis, decisões (MÉLO, 2011). Para isso, foram utilizados uma mesa, um monitor 24", um data show, um notebook, mouse e teclado.

Em seguida, os visitantes eram convidados a participar de uma dinâmica em grupo nomeada por "Nó humano" (RH PORTAL, 2016). Nesta dinâmica, as pessoas formam um círculo e deve lembrar quem está a sua direita e esquerda. Ao tocar uma música, as pessoas soltam as mãos e caminham. Quando a música para, cada um deve dar a mão para quem estava 
Conhecendo o cérebro 2018: interdisciplinaridade em um evento de extensão

primeiramente a sua direita e esquerda. Assim, surge um problema a ser resolvido: as pessoas de mãos dadas devem se organizar como estavam sem soltar as mãos. Para isso é necessário um trabalho de equipe, mostrando a importância da equipe para resolução de problemas.

Estande Equidade de Gênero

O estande Equidade de Gênero foi coordenado pela pesquisadora responsável pelo Projeto de Pesquisa "Noções de docentes de ciência acerca de educação científica para equidade de gênero" e executado por três estudantes do curso Ciências Biológicas, todas estagiárias do mesmo projeto. O objetivo foi suscitar o questionamento acerca das desigualdades de gênero no campo científico e no cotidiano das/dos visitantes.

Como recursos pedagógicos, foram utilizados um painel que retratava alguns exemplos de mulheres cientistas (crianças, jovens, adultas); atividade do "Jogo do privilégio" (jovens e adultos) e a "Dinâmica da bola" (infantil). Essas atividades eram expostas (ou não) em função da idade das/os participantes.

O recurso do painel, em que foram expostas histórias de mulheres cientistas descritas no livro Ascientistas: 50 mulheres que mudaram o mundo (IGNOTOFSKY, 2017), permitiu às expositoras realizarem uma contextualização histórica e uma breve reflexão acerca da invisibilidade feminina no campo científico para as/os visitantes.

O chamado "Jogo do privilégio" foi inspirado no "Jogo do privilégio branco" apresentado pelo Instituto Identidades do Brasil (ID-Br) e é uma dinâmica que questiona as disparidades de gênero e seu cruzamento com outros fatores de discriminação social (como classe e raça). As atividades propostas por esse jogo consistiram de questões elaboradas ou adaptadas pelas expositoras que eram dirigidas às/aos visitantes. As questões investigavam se as/os visitantes possuíam algum privilégio de gênero, raça ou classe. Os visitantes recebiam uma bala para cada resposta positiva ao privilégio e nenhuma bala para identificação negativa (sem privilégio). Ao final dos questionamentos aquelas/es que eram mais privilegiadas/os possuíam mais balas do que as/os participantes menos privilegiadas/os. A partir dos resultados do jogo, as apresentadoras convidavam as/os visitantes a uma reflexão acerca da diferenciação dos conceitos de equidade e igualdade e da necessidade de ações ou de tratamentos não necessariamente igualitários para se alcançar uma condição de igualdade de gênero e, por fim, discutiram algumas políticas públicas de equidade de gênero.

Para o público infantil, as estagiárias expuseram uma atividade lúdica, a "Dinâmica da bola", que foi baseada na dinâmica "Bola", exposta em "Coolkit-Jogos para a Não-Violência e 
Conhecendo o cérebro 2018: interdisciplinaridade em um evento de extensão

Igualdade de Género" (ROJÃO, 2011). Essa dinâmica tratava-se de uma brincadeira de roda, em que uma das participantes, sentada com as crianças, passava a bola para uma delas. A criança que pegava a bola era questionada se uma dada atividade era para meninos, meninas ou ambos. Após sua resposta, a criança passava a bola para outra/o colega responder a próxima pergunta feita pela expositora e que possuía as mesmas alternativas (e assim sucessivamente). A partir das respostas das crianças, discussões foram conduzidas com o objetivo de desnaturalizar estereótipos de gênero.

\section{RESULTADOS E ANÁLISES}

Foram mobilizados 46 alunos, sendo 29 alunos do curso de Ciências Biológicas, nove alunos de Engenharia Agronômica, oito de Ciências da Computação, um colaborador externo e quatro docentes para a realização do mesmo. Por meio da assinatura do livro de visitas, foram contabilizadas 573 assinaturas (340 do sexo feminino e 233 do sexo masculino). A idade média dos visitantes foi de $16,03 \pm 9,92$.

Em relação aos estandes propostos pelo GEN (Figura 1), as atividades mais relacionadas com o tema da Semana Nacional de Ciência e Tecnologia foram os estandes "Musicalizando", pois permitiram que as pessoas aprendessem que é possível fazer música e arte com materiais recicláveis usando a criatividade, bem como mostrar que a música pode servir como forma de se expressar. Outra atividade alusiva ao tema foi apresentada pelo estande de lógica que explicava o modo de fazer Tangram e a Torre de Hanói com materiais recicláveis e os ensinava como jogálos. Ambos os jogos estimulam o raciocínio lógico. Os demais estandes do GEN focaram em explicar o sistema nervoso central, mas especificamente a neuroanatomia (lobos e meninges) (MACHADO, 2006). Esses conteúdos foram reforçados com o estande de "Práticas artísticas" com bonecos de feltro e modelos de cérebro de biscuit baseados no livro Caçadores de neuromitos kids: em busca da verdade sobre o cérebro. Os estandes contaram com a participação dos visitantes, que fizeram perguntas para as monitoras. 
Conhecendo o cérebro 2018: interdisciplinaridade em um evento de extensão

Figura 1 -Visão geral dos estandes do GEN. A) Estande Aprenda Neuroanatomia; B) Estande Ensinando Neurociências por meio de Práticas Artísticas; C) Estande de Lógica; D) Estande Musicalizando.

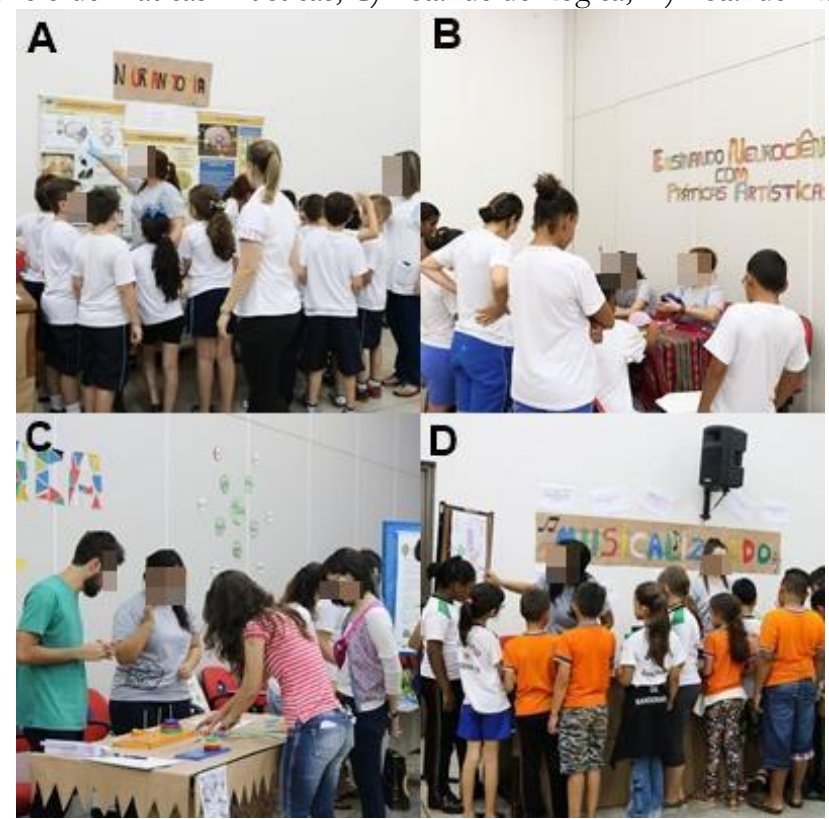

Fonte: Fotógrafa Jéssica Borges, 2018.

Em relação ao estande do NITEC (Figura 2), os visitantes demonstraram interesse, principalmente na parte de pequeno e grande produtor, pois muitos alunos achavam que havia diferença na qualidade do alimento que cada um produzia. Outro fato curioso foi que alguns não sabiam que se alimentavam de alimentos que eram derivados do trigo e da aveia. Por meio da dinâmica final (brincadeira da corrida de perguntas), os visitantes puderam mostrar o que aprenderam e esclarecer algumas dúvidas que ficaram no decorrer das apresentações.

Figura 2 - Estande do NITEC. A) Visitantes ouvindo a explicação do estande, B) Visitantes observando apresentação de slide, C) Visão geral do estande do NITEC, D) Visitantes participando da dinâmica apresentada.

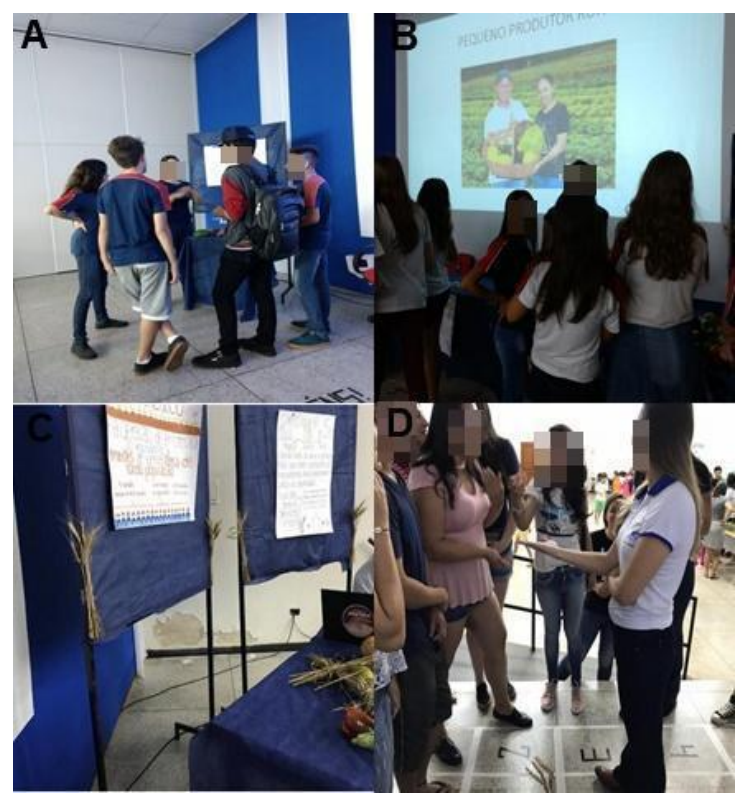


Conhecendo o cérebro 2018: interdisciplinaridade em um evento de extensão

Fonte: Fotografias dos monitores do NITEC, 2018.

Em relação ao estande do GEAK (Figura 3), no decorrer do evento foi possível observar que grande parte dos visitantes não tinha conhecimento sobre o assunto, pois a maioria disse ter pouco ou nenhum contato com o campo ou com as técnicas ligadas a agroecologia. Ao longo das explicações ministradas pelos monitores sobre o assunto, percebeu-se que os visitantes demonstraram interesse no assunto, principalmente no momento que percebiam, na maquete, a vasta diferença entre os tipos de cultura e modo de vida. Com a exposição das mudas alguns visitantes identificaram as espécies, tendo a chance de comentar onde já viu e como estava sendo utilizada, com isso a passagem do conhecimento teve duplo sentido, gerando aprendizado também para os expositores.

Figura 3 - Estande do GEAK. A) Visão da maquete, B) Apresentação do estande, C) Visitantes ouvindo a explicação, D) Plantas expostas.

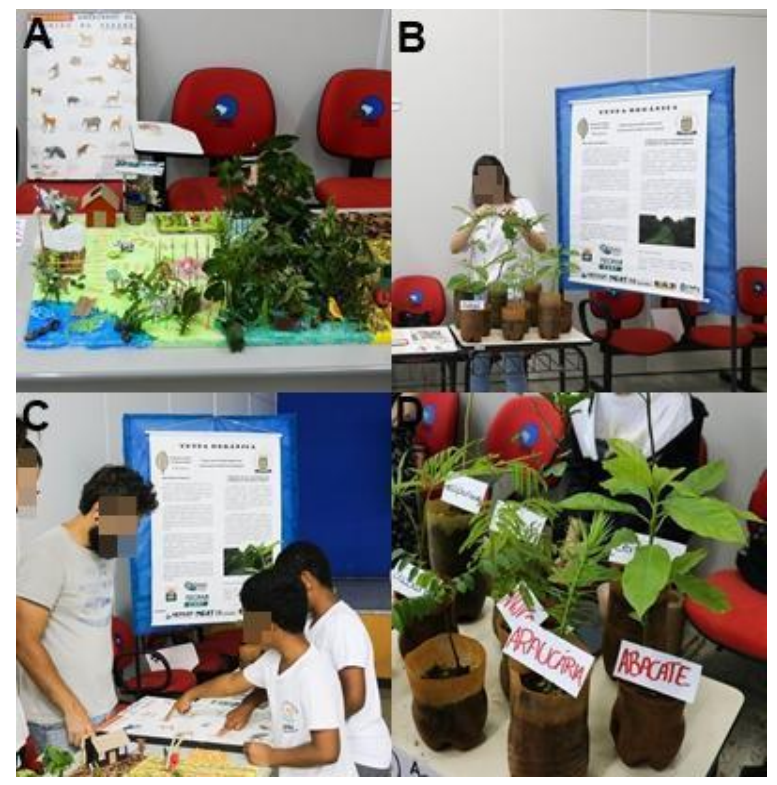

Fonte: Fotógrafa Jéssica Borges, 2018.

No estande "A ciência dos sentidos" (Figura 4), o que mais chamou a atenção dos visitantes foram as vendas. As atividades propostas nesse espaço objetivavam oferecer aos visitantes a experiência de explorar outros sentidos quando a visão fosse limitada, bem como promover a inclusão e o respeito à diversidade, mostrando que todos podem ter acesso à Ciência, independentemente de suas limitações ou deficiências.

Sendo assim, a reação do público a essas atividades seguiram certo padrão, uma vez que os visitantes, em sua maioria, sentiram-se receosos por não saber quais objetos seguravam e tocavam. Todavia, muitas pessoas, ao fim da visita no estande, afirmaram entender melhor, a 
partir daquela experiência, como um deficiente visual percebia o mundo ao seu redor por meio do tato e da audição.

Já para os alunos expositores, a experiência vivida no estande foi extremamente enriquecedora, uma vez que proporcionou a esses licenciandos o primeiro contato com o universo do deficiente visual, bem como os levou a conhecer diferentes maneiras de adaptar materiais de Ciências e Biologia para alunos cegos, de modo a incluí-los integralmente às classes regulares e potencializar os sentidos que esses alunos dispõem.

Figura 4 - Visão geral do estande do "A Ciência dos sentidos". A) Monitores envolvidos, B) Visitantes participando da

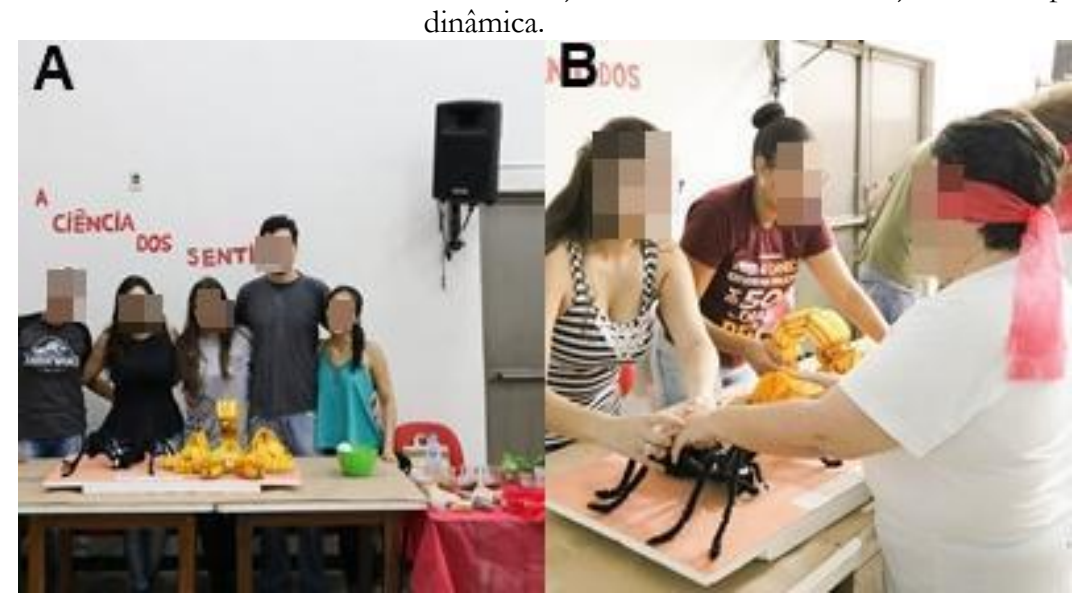

Fonte: Fotógrafa Jéssica Borges, 2018.

Em relação ao estande da Tecnologia com Setup Jr. (Figura 5A), os monitores perceberam que, por meio da vivência com tecnologias e situações apresentadas no estande, os visitantes tiveram que pensar em diferentes tipos de soluções. Alguns visitantes propuseram algumas tentativas inovadoras de atividades no Scratch. De acordo com os idealizadores dessa ferramenta, realizar atividades no Scratch, desenvolve o pensamento criativo, o raciocínio e o trabalho em equipe (SCRATCH, 2019).

Já na dinâmica em grupo "Nó humano" (Figura 5B), foi percebido que em cada grupo havia alunos proativos, com capacidade de liderança e paciência para solucionar o problema que inicialmente o grupo pensava que era insolucionável. No final, os visitantes percebiam que os problemas poderiam ser solucionados por meio de persistência e trabalho em equipe. 
Figura 5 - Visão geral do estande da Setup Jr. A) Alunos usando o Scratch; B) Dinâmica em grupo com alunos.

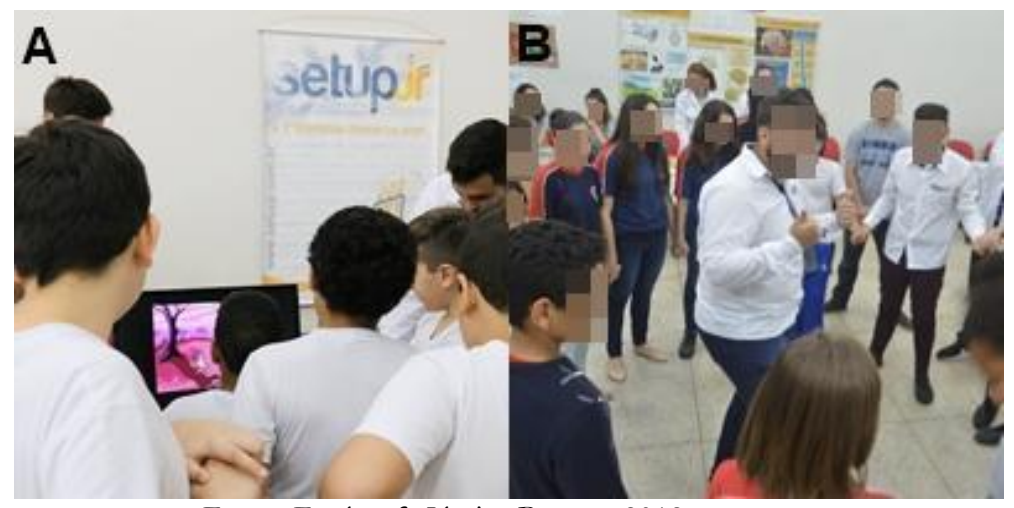

Fonte: Fotógrafa Jéssica Borges, 2018.

Por fim, no estande da Equidade de Gênero (Figura 6), as expositoras perceberam como esses eventos impactaram as/os visitantes com relação à invisibilidade de gênero e estereótipos representados para as cientistas, ao apresentarem artistas de cinema, mulheres negras, e tantas outras que se distanciam do retrato de cientistas malucas, malcuidadas e que negam sua feminilidade.

No jogo do privilégio, as expositoras se depararam com o desconhecimento dos participantes sobre a desigualdade sofrida pela maioria da população. Nas questões "Já morou ou mora em alguma área de risco?”, "Você sente ou já sentiu medo em andar na rua sozinha à noite?", "Você pode ir ao médico particular sempre que precisa?”, a maioria das/os participantes não se enquadravam nestas condições e demonstraram surpresa e certa negação para a necessidade da adoção de políticas públicas compensatórias para as desigualdades sofridas pela maioria da população.

$\mathrm{Na}$ atividade voltada às crianças, as expositoras relataram que houve maior participação e interesse das meninas e estas retratavam com maior ênfase que todas as profissões poderiam ser executadas pelos dois gêneros. Com relação aos afazeres domésticos, as meninas se posicionavam fortemente contra afirmações como "lavar louça, cozinhar e cuidar da casa é coisa de mulher".

As expositoras refletiram acerca da urgência em se tratar as questões discutidas durante apresentação do estande na futura atividade que exercerão como docentes e perceberam a necessidade de utilizar estratégias eficientes e participativas para suscitar o questionamento com relação a temas emblemáticos e necessários como o da equidade de gênero. 
Figura 6- Visão geral do estande do "Equidade de gênero". A) Monitoras envolvidas, B) Visitantes participando da dinâmica do estande.

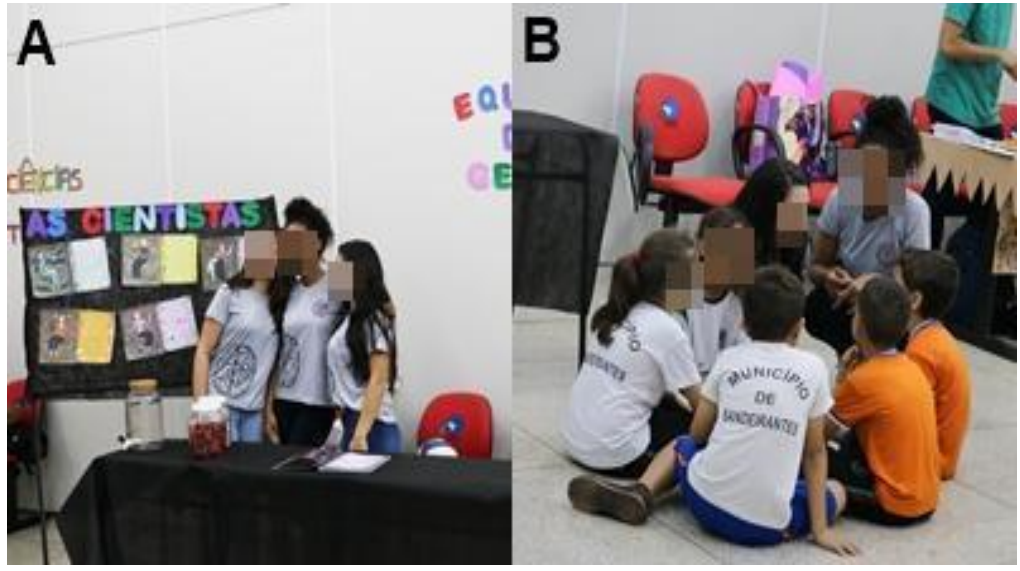

Fonte: Fotógrafa Jéssica Borges, 2018.

\section{CONSIDERAÇÕES FINAIS}

O presente evento extensionista, de caráter interdisciplinar, reuniu alunos e professores de diversos cursos da instituição. Por meio desse, pode-se observar uma troca de conhecimentos e aprendizagem mútua entre os alunos, o que evidencia tanto o papel pedagógico da extensão universitária (COELHO, 2014), pois os mesmos aprenderam no papel de alunos extensionistas, quanto a importância da interdisciplinaridade. Vale ressaltar que a interdisciplinaridade é uma premissa da extensão universitária.

Por meio da interação alunos extensionistas com a comunidade (visitantes), pode-se observar que é possível despertar o papel social da ação. Nos estandes do GEN, NITEC e GEAK, foram esclarecidas as dúvidas sobre os temas abordados nos estandes. Já no estande "A ciência dos sentidos", pode-se demonstrar as possibilidades de inclusão por meio de materiais didáticos. No estande da tecnologia com a Setup Jr., focou na resolução de problemas e trabalho em equipe, havendo uma grande interação entre os visitantes. E por fim, no estande "Equidade de gênero", o envolvimento da comunidade, em especial das meninas que participaram das atividades, demostrou que propostas como essas representam um modo eficiente para aproximar meninas da Ciência, contrapor os estereótipos de cientistas e dar visibilidade às mulheres na Ciência e de suas produções acadêmicas. 
Conhecendo o cérebro 2018: interdisciplinaridade em um evento de extensão

Além disso, percebe-se que essas ações expositivas nas quais há explicações, demonstrações, dinâmicas, podem chamar a atenção dos visitantes e ensinar conteúdos científicos de maneira divertida, o que vai ao encontro dos objetivos da divulgação científica.

\section{REFERÊNCIAS}

ALTIERI, M. A. Agroecologia, agricultura camponesa e soberania alimentar. Revista nera, n. 16, p. 22-32, 2012.

ARAUJO, E. S. N. N.; CALUZI, J. J.; CALDEIRA, A. M. A. Divulgação e cultura científica. In: ARAUJO, E. S. N. N.; CALUZI, J. J.; CALDEIRA, A. M. A (Orgs.). Divulgação cientifica e ensino de Ciências: estudos e experiências. São Paulo, Escrituras, p. 14-34, 2006.

BUENO, W. C. Comunicação científica e divulgação científica: aproximações e rupturas conceituais. Informação \& Informação, v. 15, n. esp, p. 1, 2010.

COELHO, G. C. O Papel Pedagógico Da Extensão Universitária. Em Extensão, v. 13, n. 2, p. 11-24, 2014.

EKUNI, R. et al. "Conhecendo o cérebro": divulgando e despertando interesse na neurociência. Revista Ciência em Extensão, v.12, n.2, p.125-140, 2016.

FRANCISCO, W.; SANTOS, I. H. R. A feira de ciências como um meio de divulgação científica e ambiente de aprendizagem para estudantes-visitantes. Revista Amazônica de Ensino de Ciências, v. 7, n. 13, p. 96-110, 2014.

GUILHOTO, J. JM. et al. A importância do agronegócio familiar no Brasil. Revista de Economia e Sociologia Rural, v. 44, n. 3, p. 355-382, 2006.

GUZMAN, E. S. A. Sobre la agroecologia: algunas reflexiones en torno a la agricultura familiar enespaña. p. 155-197, 1996.

IGNOTOFSKY, R. As cientistas: 50 mulheres que mudaram o mundo. Edgard Blucker Ltda., 2017.

INSTITUTO IDENTIDADES DO BRASIL ID-BR (Brasil) (Org.). Descubra o que é Jogo do Privilégio Branco. Disponível em:

http://simaigualdaderacial.com.br/site/?mergulhe_no_tema=vantagem-racial-jogo-do-privilegiobranco. Acesso em: 30 jul. 2018.

JANK, M. S.; NASSAR, A. M.; TACHINARDI, M. H. Agronegócio e comércio exterior brasileiro. Revista USP, n. 64, p. 14-27, 2005.

LORENZETTI, L.; DELIZOICOV, D. Alfabetização científica no contexto das séries iniciais. Ensaio Pesquisa em educação em Ciências, v. 3, n. 1, 2001.

MACACARE, O. T. et al. Ciência: alimento para o cérebro-uma proposta multidisciplinar de popularização da ciência. Revista Diálogos, v. 22, n. 1, p. 7-18, 2019.

MACHADO, Â.; CAMPOS, G. B. Neuroanatomia funcional. $2^{a}$ edição. São Paulo, Atheneu, 2006. 
Conhecendo o cérebro 2018: interdisciplinaridade em um evento de extensão

MÉLO, F. É. N. et al. Do Scratch ao Arduino: Uma proposta para o ensino introdutório de programação para cursos superiores de tecnologia. In: XXXIX Congresso Brasileiro de Educação em Engenharia. p. 10, 2011.

NAVEGA, S. Inteligência artificial, educação de crianças e o cérebro humano. LeopoldianumRevista de Estudos de Comunicações da Universidade Católica de Santos, p. 87-102, 2000.

OCHAÍTA, E.; ESPINOSA, A. Desenvolvimento e intervenção educativa nas crianças cegas ou deficientes visuais. In: COLL, C.; MARCHESI, A.; PALACIOS, J.(orgs) Desenvolvimento psicológico e educação. Porto Alegre: Artmed, v. 3, p. 151-170, 2004.

REAL, L. C. V.; SCHNEIDER, S. O uso de programas públicos de alimentação na reaproximação do pequeno produtor com o consumidor: o caso do programa de alimentação escolar. Revista Estudo \& Debate, v. 18, n. 2, 2011.

RH PORTAL. Dinâmica Do Nó. [S. 1.], 2016. Disponível em: https://www.rhportal.com.br/dinamicas-de-grupo/dinmica-do-n/. Acesso em: 22 jan. 2019.

ROJÃO, G. et al. Coolkit-Jogos para a Não-Violência e Igualdade de Género. Editora: Coolabora, 2011, 96p.

SABBATINI, M. Museus e centros de ciência virtuais: uma nova fronteira para a cultura científica. Comciência, Campinas, n. 45, p. 1-6, 2003.

SANTA CATARINA. Secretaria de Estado da Educação. Fundação Catarinense de Educação Especial. Guia prático para adaptação em relevo: Secretaria de Estado da Educação. Fundação Catarinense de Educação Especial, Jussara da Silva (Coord.). São José: FCEE, 2011.

SCRATCH. Acerca do Scratch. [S. 1.], 2019. Disponível em: https://scratch.mit.edu/about. Acesso em: 26 jan. 2019.

SMITH, Deborah D. Introdução à educação especial: ensinar em tempos de inclusão. Artmed Editora, 2009.

SOUZA, R. E. et al. "Conhecendo o cérebro": divulgando e despertando interesse na neurociência. Revista Ciência em Extensão, v. 12, n. 2, p. 125-140, 2016.

TOKUHAMA-ESPINOSA, T. Museosinteractivos de ciencias: cómo despertar lacuriosidad natural de losniños por laciencia y latecnología. p. 15-16, 2013.

ZEGGIO, L.; EKUNI, R.; BUENO, O. F. A. Caçadores de neuromitoskids: em busca da verdade sobre o cérebro. Florianópolis: IBIES, 2018. 46p.

ZIMMERMANN, C. L. Monocultura e transgenia: impactos ambientais e insegurança alimentar. Veredas do Direito: Direito Ambiental e Desenvolvimento Sustentável, v. 6, n. 12, 2011.

Recebido em: 31/07/2019

Aceito em: 13/03/2020 